RESENHAS / REVIEWS

RESENHA

\title{
RECONSTRUÇÃO E REFORMA DO ESTADO
}

RECONSTRUCTION AND THE REFORM

\begin{abstract}
ALBUQUERQUE, Roberto Cavalcanti de. Reconstrução e reforma do Estado. IN: VELOSO, João Paulo dos Reis; ALBUQUERQUE, Roberto Cavalcanti de (coord.). Governabilidade e Reformas. Rio de Janeiro: José Olympio, 1995. p. 129-198.
\end{abstract}

\section{Lara Caxico Martins Miranda ${ }^{1}$}

Como citar: MIRANDA, Lara Caxico Martins. Reconstrução e reforma do Estado. Revista do Direito Público, Londrina, v. 12, n. 2, p. 308-315, ago. 2017. DOI: 10.5433/1980-511X.2017v12n2p308

Roberto Cavalcanti de Albuquerque, em seu trabalho intitulado “Reconstrução e Reforma do Estado", publicado na obra Governabilidade e Reformas, pretende analisar as transformações ocorridas na década de 90 em virtude da Reforma Administrativa do Estado. No período, a descentralização organizacional envolvendo a esfera pública e a privada se fizeram latentes, demonstrando a necessidade de um novo olhar sobre a postura de prestação de serviços públicos. Em sua pesquisa, o autor revela ainda a urgência de se consolidar um Estado em que as entidades

\footnotetext{
1 Mestranda em Direito Negocial pela Universidade Estadual de Londrina. Professora de Direito do Trabalho nas Faculdades Integradas do Vale do Ivaí (UNIVALE) e professora de Direito Constitucional para cursos preparatórios para concursos na Instituição Saber (Londrina). Pós Graduada em Direito Constitucional pelo Complexo de Ensino LFG e em Direito do Trabalho e Processo do Trabalho pelo Damásio. Possui graduação em Direito pela Universidade Estadual de Londrina laracaxico@hotmail.com
} 
federativas efetivamente participem da promoção de serviços sociais de maneira autônoma e voltada para o interesse coletivo.

Além da dimensão social, o novo modelo administrativo apresenta uma importante dimensão política, vez que aperfeiçoa instituições de atuação popular e incorpora novas práticas democráticas, atuando na universalização do exercício da cidadania (ALBUQUERQUE, 1995, p. 133). Nesse viés, Albuquerque (1995, p. 147) define alguns princípios norteadores da reestruturação do Estado. Afirma o autor que o princípio basilar é a "sociedade politicamente organizada", vez que essa compreende a própria essência do Estado. Há a necessidade de uma vivência social e política efetiva da população nos rumos do Estado, pois essa é capaz de assegurar a permanente aderência aos interesses coletivos através do controle social.

Trata-se de garantir a real representatividade social por meio de um legítimo processo político eleitoral, desenvolver mecanismos de influência nas decisões da administração e de aperfeiçoar os meios de controle dos negócios públicos. Ações essas que confluem para uma “[...] mudança na cultura política que sanciona, na práxis de governo, Estado concebido como a instituição política da sociedade" (ALBUQUERQUE, 1995, p. 147). Para Albuquerque (1995, p. 147) isso significa "[...] compreender e organizar a sociedade como nação que se prolonga no Estado". O Estado, como parte da nação e por ela constituído, deve ter suas ações voltadas para o atendimento dos interesses dessa, ainda que em algumas situações precise subordinar interesses particulares.

No âmbito econômico, a reforma propõe ainda a convergência de alguns pontos da atuação da esfera pública e da esfera privada. Dentre os paradigmas da nova gestão, o modelo de administração busca na iniciativa privada mecanismos que tragam maior eficiência para o mover 
da máquina pública. A isso se chama, de acordo com Albuquerque (1995, p. 152) paradigma empresarial de governo. Não significa abandonar mandamentos constitucionais e legais que dispõem sobre a organização do Estado e prestação dos serviços públicos, mas sim uma atuação voltada a servir os "clientes" do Estado, que se compreendem, em última instância, no povo, que deve avaliar o desempenho administrativo como contribuintes-consumidores (ALBUQUERQUE, 1995, p. 153). Segundo o autor,

O uso mais amplo e criativo de práticas empresariais e competitivas na prestação de serviços públicos - seja por agências governamentais, seja pela iniciativa privada ou por organizações da comunidade - poderá contribuir grandemente para mais eficiência e maior satisfação de contribuintes e usuários, inclusive em áreas como saúde, educação, previdência e assistência social (ALBUQUERQUE, 1995, p. 154).

A eficiência, subdividida em eficácia e efetividade, associada à equidade e subsidiariedade compõem os princípios norteadores da atuação administrativa privada que devem transformar a atuação administrativa pública. Estes dão fundamento à transferência de determinadas atividades, antes prestadas unicamente pelo Estado, ao particular, após uma minuciosa observância daqueles que se colocam como mais aptos e eficazes na utilização dos recursos sociais.

A iniciativa privada, em virtude da sua característica essencial de competitividade, possui em algumas áreas mais e melhores mecanismos de execução de serviços, o que faz com que o atendimento ao cidadão 
seja mais eficiente. Por essa razão, a reforma aponta para a necessidade de que "[...] o Estado como um todo deve conceder à esfera privada o que puder ser, nesse entendimento, por ela mais bem executado" (ALBUQUERQUE, 1995, p. 151).

Como mecanismo da reforma, Estado passa a equilibrar as finanças públicas e a descentralizar suas atividades. As estratégicas ações governamentais se tornam mais seletivas e eficazes, indicando uma nova governabilidade atenta à "[...] prestação de serviços cuja eficiência e qualidade devem ser aferidas pelo grau de satisfação manifestado pelos contribuintes-consumidores" (ALBUQUERQUE, 1995, p. 134).

$O$ princípio da descentralização administrativa se faz necessário para a reforma, a medida em que o deslocamento de diversos encargos e recursos União para estados e municípios e para novas pessoas jurídicas da chamada administração indireta permitem especialização do serviço e prestação mais eficiente (ALBUQUERQUE, 1995, p. 147).

Nesse contexto, a descentralização e privatização devem, por um lado, ser vistas como meios de alcançar-se maior eficiência e equidade, bem como para que se reduzam os encargos que agigantam o Estado (a União em particular), sobrecarregando-lhe a administração e inviabilizando suas finanças. E, por outro, como mecanismos que viabilizem federalismo de integração e parcerias responsáveis e convergentes entre as esferas pública e privada da sociedade (ALBUQUERQUE, 1995, p. 152).

A reforma não representa, em nenhuma hipótese, uma 
diminuição do poderio do Estado, vez que este continua a “[...] exercer seu papel regulamentador, regulador e fiscalizador da prestação desses serviços, segundo parâmetros estabelecidos normativa, convencional ou contratualmente". Ao contrário disso, a nova gestão pública preserva a característica essencialmente republicana, vez que permanece com sua atuação subordinada aos princípios da "[...] legalidade, impessoalidade e publicidade, assegurados pelo controle sócio-político sobre ele exercido" (ALBUQUERQUE, 1995, p. 151). A descentralização de políticas públicas se volta à prestação eficiente de serviços sociais e garante a manutenção do viés de Estado Social (ALBUQUERQUE, 1995, p. 165).

Segundo o Albuquerque (1995, p. 164 - 165), as iniciativas estatais relacionadas à nova administração devem pautar-se, primeiramente, na melhoria da prestação de serviços sociais, com destaque para a saúde e a educação. Para tanto, faz-se necessário descentralizar a prestação de serviços, garantindo que os entes da administração direta mais próximos da população, como Municípios, e pessoas jurídicas da Administração indireta, como autarquias, realizem tais atividades. Isso porque "[...] existe razoável consenso de que a eficiência na prestação de serviços sociais públicos pode ser mais facilmente obtida quando eles são executados por organismos que se situam mais próximos de seus usuários" (ALBUQUERQUE, 1995, p. 167).

A descentralização se coloca como mais um desafio para o Estado Federado brasileiro, a medida em que passa a exigir que o ente inicialmente centralizador reparta as competências para a prestação de serviços públicos, inicialmente com as demais entidades da própria administração direta. Nessa distribuição é preciso manter a coesão entre os governos que mais executam as políticas sociais, Estados e Municípios, 
e aqueles que realizam a transferência, União e Estados. "Cabe indiscutivelmente à União, no que respeita às políticas sociais públicas, liderar esforço concentrado, coerente e convergente de integração de decisões e de ações, orientado pelos objetivos de eficiência e equidade" (ALBUQUERQUE, 1995, p. 168).

Os novos modelos de atuação buscam observar as diversidades regionais, o desenvolvimento local, e consequentemente asseguram "[...] à ação social de governo mais eficiência e equidade" (ALBUQUERQUE, 1995, p. 166). No âmbito da saúde, por exemplo, destaca o autor que não é aconselhável criar um modelo único e aplicá-lo a toda federação. Isso porque este seria útil em algumas regiões e em outras não se prestaria ao atendimento social. Por meio da descentralização e da conferência de real autonomia governamental aos Estados e Municípios é possível garantir que esses criem políticas adequadas às necessidades da população (ALBUQUERQUE, 1995, p. 169).

No caso da saúde, especificamente, caberia à União apenas “[...] ater-se ao planejamento, regulação, definição de objetivos e cofinanciamento" enquanto que os Municípios se ocupariam da prestação dos serviços essenciais e os Estados de serviços mais especializados e que necessitassem de alta tecnologia (ALBUQUERQUE, 1995, p. 166).

O modelo de descentralização, como é perceptível nas considerações do autor, não deve garantir a distribuição apenas da execução do serviço, mas também e principalmente, a conferência de autonomia político-administrativa, caracterizada na capacidade de auto-organização, auto legislação e autoadministração. Assim, “[...] a descentralização pode ser um bom remédio para combater a esclerose burocrática e despertar a capacidade de autogestão e a criatividade da sociedade, estimulando mais competitividade e maior controle social" 
(ALBUQUERQUE, 1995, p. 166).

No que se refere à descentralização para a iniciativa privada, o autor expõe o posicionamento de defesa da privatização pura de alguns autores. Afirma esse que, aqueles favoráveis às privatizações se pautam em um paradigma neoliberal de Estado mínimo que atua apenas nas funções essencialíssimas. Para Albuquerque, por sua vez, não é cabível se pensar em transferir totalmente o eixo decisório da sociedade para o mercado, vez que isso enfraqueceria o próprio Estado. Seria necessário desenvolver a interação entre os eixos decisórios, de modo a manter as posições estratégicas sob o comando estatal e permitir que o mercado articule, sob a regulação do Estado, as forças econômicas. "Essa opção de organização da sociedade pressupõe um Estado fortalecido e confiante em seu poder de ordenar e regular, em acordo com o interesse coletivo, as atividades econômicas exercidas pela iniciativa privada" (ALBUQUERQUE, 1995, p. 174).

Seguindo tais paradigmas, a privatização permite que o Estado atue de maneira mais seletiva, escolhendo para ele a prestação de serviços que efetivamente exijam a movimentação da máquina estatal. Serviços esses essenciais, estratégicos e que não enfraquecem, mas sim positivam a força do Estado. O repasse para a iniciativa privada de atividades que não justificam mais a atuação do Estado faz com que esse se desonere e garanta um serviço de qualidade, sem que com isso deixe de regular o setor e implementar políticas de incentivos quando assim entender necessário (ALBUQUERQUE, 1995, p. 174-175).

Para Albuquerque (1995, p. 177), a privatização da prestação de serviços públicos foi formalmente garantida pela Constituição da República Federativa do Brasil de 1988 na norma do artigo 175, que garante a possibilidade de o Poder Público prestar serviços públicos sob o 
regime de concessão e permissão. Somando a autorização constitucional, ao fato de que a privatização garante a melhoria da prestação de serviços à sociedade e que o Estado é a sociedade politicamente organizada, é certo que essa, quando devidamente implementada e sob o controle do Estado, deve ser mecanismo a ser utilizado na reforma.

Cumpre concluir afirmando que o autor indica que a descentralização e a privatização não são propostas novas na década de 90 , tendo em vista que essas já vinham sendo implementadas no Brasil no período da redemocratização, a partir de meados da década de 70 (ALBUQUERQUE, 1995, p. 165). Apesar disso, os institutos precisam ser desenvolvidos e para isso se presta a reforma administrativa gerencial. É possível se afirmar que o estudo propõe uma administração pública eficiente a ser desenvolvida com a reforma administrativa, em que o Estado não seja responsável pelo fornecimento de todo e qualquer serviço, mas sim que atue nas áreas estratégicas e de essencial movimento da máquina pública.

Como citar: MIRANDA, Lara Caxico Martins. Reconstrução e reforma do Estado. Revista do Direito Público, Londrina, v. 12, n. 2, p. 308-315, ago. 2017. DOI: 10.5433/1980-511X.2017v12n2p308

Recebido em: 05/07/2017

Aprovada em: 22/08/2017 